CLINICAL STUDY

\title{
Impaired aerobic exercise adaptation in children and adolescents with craniopharyngioma is associated with hypothalamic involvement
}

\author{
Xavier Piguel $^{2}$, Pierre Abraham ${ }^{3,4}$, Natacha Bouhours-Nouet ${ }^{1,5}$, Frédérique Gatelais ${ }^{1}$, Sylvie Dufresne ${ }^{1}$, \\ Stéphanie Rouleau ${ }^{1}$ and Régis Coutant ${ }^{1,4,5}$ \\ ${ }^{1}$ Department of Pediatric Endocrinology, Angers University Hospital, 4 rue Larrey, 49033 Angers Cedex 01, France, ${ }^{2}$ Department of Endocrinology, \\ Poitiers University Hospital, Poitiers, France, ${ }^{3}$ Department of Physiology and Sports Medicine, Angers University Hospital, Angers, France, ${ }^{4}$ UMR \\ CNRS771/INSERM 6214, Angers, France and ${ }^{5}$ Center for Rare Diseases in Hormonal Receptivity, Angers University Hospital, Angers, France \\ (Correspondence should be addressed to R Coutant at Department of Pediatric Endocrinology, Angers University Hospital; Email: recoutant@chu-angers.fr)
}

\begin{abstract}
Objective: Many patients treated for craniopharyngioma (CP) complain of a relative incapacity for physical activity. Whether this is due to an objective decrease in adaptation to exercise is unclear. We assessed exercise tolerance in children with surgically treated CP and appropriate pituitary hormone replacement therapy compared with healthy controls and we examined the potential relationships with hypothalamic involvement, GH replacement, and the catecholamine deficiency frequently observed in these subjects.

Design and methods: Seventeen subjects (12 males and five females) with CP and 22 healthy controls (14 males and eight females) aged 15.3 \pm 2.5 years (7.3-18 years) underwent a standardized cycle ergometer test. Maximum aerobic capacity was expressed as the ratio of $\mathrm{VO}_{2 \max }$ to fat-free mass $\left(\mathrm{VO}_{2 \max } / \mathrm{FFM}\right)$, a measure independent of age and fat mass in children.

Results: $\mathrm{VO}_{2 \max } / \mathrm{FFM}$ was $20 \%$ lower in children with $\mathrm{CP}$ compared with controls $(P<0.05)$, even after adjustment for gender. Children with hypothalamic involvement $(n=10)$ had a higher percentage of fat mass $(P<0.05)$ than those without hypothalamic involvement $(n=7)$ and lower $\mathrm{VO}_{2 \max } / \mathrm{FFM}$ $(P<0.05)$, whereas children without hypothalamic involvement had $\mathrm{VO}_{2 \max } / \mathrm{FFM}$ close to that of controls $(P>0.05)$. GH treatment was associated with a significant positive effect on aerobic capacity $(P<0.05)$ only in the absence of hypothalamic involvement. No relationship was found between exercise capacity parameters and daily urine epinephrine excretion or epinephrine peak response to insulin-induced hypoglycemia.

Conclusions: Children with CP have a decrease in aerobic capacity mainly related to hypothalamic involvement. The hypothalamic factors altering aerobic capacity remain to be determined.
\end{abstract}

European Journal of Endocrinology 166 215-222

\section{Introduction}

Despite appropriate pituitary hormone substitutive treatment, general quality of life is often impaired in adult as well as pediatric patients treated for craniopharyngioma (CP), especially on physical subscales $(1,2,3,4,5)$. Most patients complain of fatigue and reduced physical activity (1). A decrease in movement counts has been shown in affected children using an accelerometer (6). Whether the decline in physical activity is due to depression and a general feeling of fatigue $(1,7)$, to obesity (8), or directly due to an objective lack of adaptation to exercise is unknown: no evaluation of exercise performance, including maximal oxygen uptake, has been specifically performed in adult or pediatric patients with CP.

Impaired exercise performance has been extensively studied in subjects with GH deficiency (GHD) $(9,10)$.
Placebo-controlled trials have shown an improvement in aerobic capacity in adults by GH replacement (11). Most of the studied subjects had multiple pituitary hormone deficiencies and were receiving appropriate replacement therapies. No similar study has been performed in children, although in adults with childhood-onset GHD solely, no significant improvement in exercise capacity was found upon GH replacement (11). These discrepancies could be due to the cause rather than the age of GHD onset: pituitary macroadenoma, the main cause of adult-onset GHD, is virtually nonexistent in children (12).

The main objective of this study was to assess exercise tolerance using a standardized high-intensity cycle ergometer test in 17 children and adolescents with surgically treated $\mathrm{CP}$, a unique cause of pituitary hormone deficiency, and appropriate pituitary hormone 
replacement therapy, compared with 22 healthy controls matched for age, gender, height, body mass index (BMI), percent body fat, and weekly sports volume. Maximal aerobic capacity was expressed as the ratio of both $\mathrm{VO}_{2 \max }$ to body weight and $\mathrm{VO}_{2 \max }$ to fat-free mass (FFM), as the latter measure is independent of age in this age range $(13,14,15)$. Since several factors could theoretically contribute to alterations in exercise capacity in affected subjects, including homeostatic dysfunction due to hypothalamic involvement (8), a defect in epinephrine secretion $(16,17,18)$, or insufficient pituitary hormone replacement therapy including GH, we also studied the impact of $\mathrm{GH}$ replacement, epinephrine deficiency, and hypothalamic involvement on parameters of exercise capacity.

\section{Materials and methods}

\section{Subjects}

Children with CP Seventeen children with CP (12 males and five females) were studied; 14 had undergone transcranial surgery and three, transnasal surgery. Surgery had been performed 1.0-15.0 years before the study. The age range was 7.3-18.0 years at the time of the study. Ten had had a tumor with hypothalamic involvement, as classified by Puget et al. (19): preoperative magnetic resonance imaging showed no identifiable hypothalamus and/or postoperative magnetic resonance imaging showed hypothalamic damage (up to no identifiable floor of the third ventricle). Postoperatively, all the children had at least two pituitary hormone deficiencies (17 with GHD, 17 with TSH deficiency, 15 with corticotropin deficiency, 14 with certain gonadotropin deficiency (as they had not gone through puberty at the usual age and needed sex steroid substitution), and 16 with diabetes insipidus) and were receiving appropriate hormone replacement therapy. All the subjects received levothyroxine $(2.0 \pm 0.6 \mu \mathrm{g} / \mathrm{kg})$ leading to circulating free $\mathrm{T}_{4}$ levels of $15.6 \pm 4.8 \mathrm{pmol} / \mathrm{l}$ (normal value $=10-23)$ and 15 received hydrocortisone (10.3 $\pm 2.0 \mathrm{mg} / \mathrm{m}^{2}$ of body surface area). All had received rhGH replacement $(30 \pm 11 \mu \mathrm{g} / \mathrm{kg}$ per day): among them, six were still on rhGH treatment because they were growing and 11 had stopped rhGH treatment 6 months to 2 years earlier because they had reached their adult height. Fourteen subjects received sex steroid (testosterone enanthate in males, $17 \beta$-estradiol in females) and 16 received desmopressin replacement (plasma $\mathrm{Na}$ $141 \pm 3 \mathrm{mmol} / \mathrm{l})$. Hemoglobin measurement was $14.5 \pm 1.5 \mathrm{~g} / \mathrm{dl}$ and capillary $\mathrm{PO}_{2}$ was $98 \pm 1 \mathrm{mmHg}$.

Control group for cycle ergometer test Twenty-two healthy children (14 males and eight females) agreed to participate in the study. All were in good health and none was taking medication. The age range was $11.0-18.0$ years.
Short children group for catecholamine study To establish normative data in children for epinephrine, and norepinephrine in response to insulin, as well as for urinary catecholamines, 17 healthy short children were studied. They were comparable for age $(14.4 \pm 1.1$ years, 7.9-17 years), gender (11 males and six females), and pubertal stage (11 subjects were in puberty and six were prepubertal) to the children with CP. These children had primarily been referred for assessment of GH secretion using an insulin tolerance test (ITT) because of short stature and/or decreasing growth velocity. GHD was ruled out (GH peak to the ITT $>20 \mathrm{mUI} / \mathrm{l})$. The children were all in good health and none had gonadotropin deficiency, hypothyroidism, chromosomal abnormalities, dysmorphic syndromes, skeletal dysplasia, chronic illness, or any endocrine or metabolic disease. None was taking medication.

In subjects with $\mathrm{CP}$ as well as in controls, height and weight were measured (20), BMI was calculated (21), and body composition was measured using bioelectric impedance analysis (Body stat QuadScan 4000; Bodystat, Isle of Man, UK), a method validated in children $(22,23)$. Pubertal stage was assessed by physical examination according to the Tanner criteria $(24,25)$. Subjects were asked how many hours per week they engaged in strenuous physical activities, such as bicycling, running, swimming laps, and playing soccer, basketball, tennis, or badminton, under a coach's supervision.

Protocols were approved by our institutional review board. All subjects and families gave their informed consent.

\section{Study design}

Cycle ergometer test Each subject underwent a maximal incremental exercise test to determine maximal aerobic capacity. The children with CP received their usual hormone replacement therapy. All exercise tests were monitored by a physician and performed in the morning after an overnight fast (water permitted). Subjects were instructed to abstain from caffeinated foods and drinks, alcohol, and strenuous exercise for at least $24 \mathrm{~h}$ before each exercise session. The guidelines for exercise testing published by the American Heart Association were observed (26). All exercise tests were performed on a cycle ergometer (Sensor-Medics Ergoline 800, SensorMedics Corp., Yorba Linda, CA, USA). Subjects were prepped with electrodes for continuous monitoring with a 12-lead electrocardiogram (MAX 1, SensorMedics Corp.) and fitted with a nose clip and mouthpiece assembly for measurement of oxygen uptake $\left(\mathrm{VO}_{2}\right)$ and carbon dioxide production by open-circuit spirometry (SensorMedics $\mathrm{V}_{\text {max }}$ ). Variables measured included $\mathrm{VO}_{2}$, carbon dioxide, heart rate, blood pressure (BP), respiratory exchange ratio, and spirometry parameters (27). 
After exercising, subjects recovered by pedaling with unloaded resistance until heart rate returned to under 120 beats/min and then by sitting in a chair. All subjects underwent a maximal incremental cycle ergometer test to volitional exhaustion to document their maximal aerobic capacity $\left(\mathrm{VO}_{2 \max }\right)$. The maximal test involved a 3-min warm up (with unloaded pedaling resistance) followed by a continuous increase in work rate until the subject could go no further. The work rate increase for each subject was determined based on predicted maximal power and was designed to elicit maximal effort within 8-12 min. The $\mathrm{VO}_{2}$ during the final $20 \mathrm{~s}$ of exercise was used as a measure of $\mathrm{VO}_{2 \max }$. When the rating of perceived exertion was $>17$ using the revised Borg scale (28), $\mathrm{VO}_{2 \max }$ was defined by at least two of the following criteria: i) plateau in $\mathrm{VO}_{2}$ at $2.0 \mathrm{ml} / \mathrm{kg}$ per min or less; ii) heart rate within $5 \%$ of 195 beats/min; and iii) respiratory exchange ratio 1.10 or greater. $\mathrm{VO}_{2 \max }$ and $\mathrm{VCO}_{2 \max }$ were expressed in milliliter per minute (standard temperature pressure and dry). To avoid the confounding effect of age and height on aerobic capacity, we expressed $\mathrm{VO}_{2 \max }$ and $\mathrm{VCO}_{2 \text { max }}$ per unit of body weight and per unit of FFM, as the latter measure was shown to be independent of age, height, and fat mass in children $(13,14,15)$.

Catecholamine study A standardized ITT was performed after a physiological overnight fast in both the children with $\mathrm{CP}$ and the children referred for short stature. After placement of a catheter in a peripheral vein, regular insulin was injected i.v. at a dose of $0.1 \mathrm{U} / \mathrm{kg}$ at $0800 \mathrm{~h}$. Blood samples were collected at 0,30 , and $60 \mathrm{~min}$ for epinephrine and norepinephrine measurements. After the insulin-induced hypoglycemia test, the subjects were allowed to stand up, and after $5 \mathrm{~min}$, blood samples were taken for the measurement of plasma catecholamines (orthostatic test). The day after the ITT, 24-h urine specimens were obtained for catecholamine measurement in both the children with $\mathrm{CP}$ and the children referred for short stature, whereas the patients with $\mathrm{CP}$ were taking their usual hormone replacement doses.

\section{Assays}

Plasma epinephrine and norepinephrine were measured by HPLC with electrochemical detection $(16,29)$. Sensitivity was $50 \mathrm{ng} / \mathrm{l}(0.27 \mathrm{nmol} / \mathrm{l})$, and the intra- and inter-assay coefficients of variation were $<5$ and $10 \%$, respectively, at every level. Urinary epinephrine and norepinephrine were measured by HPLC with electrochemical detection (30). Detection limits for epinephrine and norepinephrine were $1 \mu \mathrm{g} / \mathrm{l}$ $(5.5 \mathrm{nmol} / \mathrm{l})$ and $1 \mu \mathrm{g} / \mathrm{l}(5.9 \mathrm{nmol} / \mathrm{l})$ respectively. Intra- and inter-assay coefficients of variation for catecholamines were $<3 \%$.

\section{Statistical analysis}

Quantitative variables that were normally distributed, as assessed by the Kolmogorov-Smirnov test, were expressed as mean \pm s.D., whereas non-normally distributed variables were expressed as medians (25th, 75 th percentile). Quantitative variables were compared using ANOVA (without and with adjustment on gender), Fisher's least significant difference post hoc tests and Student's t-tests (for normally distributed variables), and the Mann-Whitney $U$ test (for nonnormally distributed variables). Qualitative variables were compared using the $\chi^{2}$ test. Pearson's correlations were performed. $P<0.05$ was considered significant. To study the combined effect of GH replacement and hypothalamic involvement on maximal aerobic capacity, multiway ANOVA was performed, with GH replacement (no $=0$, yes $=1$ ) and hypothalamic involvement ( $\mathrm{no}=0$; yes $=1$ ) as explanatory variables and gender as a covariate. Statistical tests were performed using the SPSS 16.0 statistical package (SPSS, Inc., Chicago, IL, USA).

\section{Results}

\section{Characteristics of the children with CP and healthy controls}

Mean age was $15.3 \pm 2.5$ years, with no difference between the 17 children with $\mathrm{CP}$ and the 22 controls (P>0.05; Table 1). Mean age, height SDS, BMI SDS, percent fat mass, FFM, and median weekly sports volume were similar in children with $\mathrm{CP}$ and healthy controls, in females with $\mathrm{CP}$ and female controls, and in males with $\mathrm{CP}$ and male controls. Gender and puberty distributions were similar in the two groups. Mean time since the last surgery was $5.7 \pm 4.0$ years (1-15 years).

\section{Cycle ergometer test in children with $\mathrm{CP}$ and healthy controls}

$\mathrm{VO}_{2 \text { max }}, \mathrm{VCO}_{2 \max }$, peak systolic $\mathrm{BP}$, and systolic BP increment were significantly lower in the children with CP compared with controls $(P<0.05$ for all comparisons), whereas maximal heart rate and respiratory quotient were similar, indicating that the effort was equally maximal in the two groups. Similarly, the ratios of $\mathrm{VO}_{2 \max }$ to body weight $\left(\mathrm{VO}_{2 \max } / \mathrm{BW}\right)$ and $\mathrm{VO}_{2 \max }$ to FFM $\left(\mathrm{VO}_{2 \max } / \mathrm{FFM}\right)$ were significantly lower in the children with $\mathrm{CP}$ compared with controls $(P<0.05$ for the two comparisons) (Table 2), even after adjustment for gender. $\mathrm{VO}_{2 \text { max }} / \mathrm{BW}$ and $\mathrm{VO}_{2 \text { max }} / \mathrm{FFM}$ were not related to age, height, or pubertal stage. The exclusion of the prepubescent children did not change the significance of the comparisons. 
Table 1 Characteristics of the children. Normally distributed variables were expressed as mean \pm s.D., whereas non-normally distributed variables were expressed as medians (25th, 75th percentile). Comparisons between groups were performed using Student's $t$-test and Mann-Whitney $U$ test.

\begin{tabular}{llllll}
\hline & \multicolumn{3}{c}{ Craniopharyngioma } \\
\cline { 2 - 4 } & With HI $(n=7)$ & Without HI $(n=10)$ & Total $(n=17)$ & $\begin{array}{l}\text { Healthy normal } \\
\text { children }(n=22)\end{array}$ & $\boldsymbol{P}^{\star}$ \\
\hline Age (years) & $15.4 \pm 3.4$ & $15.1 \pm 3.4$ & $15.2 \pm 3.3$ & $15.4 \pm 1.8$ & $\mathrm{NS}$ \\
Gender (M/F) & $1 / 6$ & $4 / 6$ & $12 / 5$ & $14 / 8$ & $\mathrm{NS}$ \\
Puberty (yes/no) & $5 / 2$ & $9 / 1$ & $14 / 3$ & $19 / 3$ & $\mathrm{NS}$ \\
Height (SDS) & $0.0 \pm 1.2$ & $0.7 \pm 1.3$ & $0.4 \pm 1.3$ & $0.0 \pm 1.2$ & $\mathrm{NS}$ \\
BMI (SDS) & $0.4 \pm 0.8^{\mathrm{b}}$ & $2.1 \pm 1.5$ & $1.4 \pm 1.5$ & $1.2 \pm 1.6$ & $\mathrm{NS}$ \\
Percent fat mass & $20.6 \pm 3.9^{\mathrm{b}}$ & $32.2 \pm 10.9$ & $27.4 \pm 10.4$ & $24.4 \pm 10.0$ & $\mathrm{NS}$ \\
Fat-free mass (kg) & $43.0 \pm 11.4$ & $46.8 \pm 14.6$ & $45.2 \pm 13.1$ & $46.1 \pm 5.6$ & $\mathrm{NS}$ \\
Sport (hours/week) & $4.0(4.0 ; 6.0)$ & $4.0(4.0 ; 5.3)$ & $4.0(4.0 ; 5.5)$ & $4.0(4.0 ; 6.0)$ & \\
\hline
\end{tabular}

$\mathrm{HI}$, hypothalamic involvement. * , refers to comparison between total $\mathrm{CP}$ and normal children.

a'For children with craniopharyngioma, puberty was rated 'yes' when patients received sex steroid treatment and 'no' when they did not receive such treatment.

${ }^{\mathrm{b}} \mathrm{P}<0.05$ between $\mathrm{CP}$ with and without $\mathrm{HI}$.

\section{Impact of rhGH replacement and hypo- thalamic involvement on children with CP}

Children with hypothalamic involvement $(n=10)$ had comparable age, height SDS, and weekly sports volume to children without hypothalamic involvement (Table 1). BMI SDS (2.1 \pm 1.5 vs $0.4 \pm 0.8$ SDS) and percent fat mass $(32.2 \pm 10.9$ vs $20.6 \pm 3.9 \%)$ were significantly higher in subjects with hypothalamic involvement $(P<0.05)$, whereas FFM was similar. Maximal heart rate and peak respiratory exchange rate were similar between children with and without hypothalamic involvement. However, $\mathrm{VO}_{2 \max } / \mathrm{BW}$ and $\mathrm{VO}_{2 \max } / \mathrm{FFM}$ were lower in children with hypothalamic involvement compared with those without hypothalamic involvement $(P<0.05$ for the two comparisons) and were similar between CP children without hypothalamic involvement and controls $(P>0.05)$ : $24.3 \pm 6.4, \quad 36.9 \pm 10.0$, and $37.8 \pm 10.9 \mathrm{ml} / \mathrm{kg}$ per min for $\mathrm{VO}_{2 \max } / \mathrm{BW}, 35.5 \pm 6.6,45.0 \pm 10.1$, and $49.5 \pm 10.8 \mathrm{ml} / \mathrm{kg}$ per min for $\mathrm{VO}_{2 \mathrm{max}} / \mathrm{FFM}$, in $\mathrm{CP}$ children with and without hypothalamic involvement and controls respectively (Fig. 1). This remained true after adjustment for gender.

Since six of the CP children were being treated with rhGH (see Materials and methods section), we examined the combined effect of hypothalamic involvement and rhGH treatment on aerobic performance. Multiway ANOVAs were performed, with gender as a covariate (Table 3). Hypothalamic involvement was significantly associated with $\mathrm{VO}_{2 \max } / \mathrm{FFM}(-20.6 \pm 6.2 \mathrm{ml} / \mathrm{kg}$ per min in cases of hypothalamic involvement, $P=0.01$ ), although rhGH treatment alone was not; however, rhGH treatment interacted with hypothalamic involvement to affect $\mathrm{VO}_{2 \max } / \mathrm{FFM}(P=0.03)$ : rhGH treatment was associated with a significant increase of 18.7 $\pm 7.3 \mathrm{ml} / \mathrm{kg}$ per min in $\mathrm{VO}_{2 \text { max }} / \mathrm{FFM}$ only in the absence of hypothalamic involvement (Table 3). Similar results were found with $\mathrm{VO}_{2 \max } / \mathrm{BW}$ as the dependent variable (not shown).

\section{Influence of epinephrine deficiency on aerobic capacity of children with $\mathbf{C P}$}

The children with $\mathrm{CP}$ had significantly lower peak epinephrine and significantly higher peak norepinephrine in response to the ITT than short normal controls $(P<0.05$ for all comparisons, Table 4). In agreement, urinary epinephrine was lower in the children with $\mathrm{CP}$ than in the controls $(P<0.05)$.

Correlation analyses were performed between exercise capacity parameters $\left(\mathrm{VO}_{2 \max } / \mathrm{BW}\right.$ or $\left.\mathrm{VO}_{2 \max } / \mathrm{FFM}\right)$, systolic BP increment during exercise, peak epinephrine and

Table 2 Exercise capacity and cardiorespiratory response during the standardized exercise test in patients with craniopharyngioma and in healthy controls. Comparisons between groups were performed using Student's $t$-tests. Percentage of predicted FVC and $\mathrm{FEV}_{1}$ was calculated according to Quanjer et al. (27).

\begin{tabular}{|c|c|c|}
\hline & $\begin{array}{c}\text { Cranio- } \\
\text { pharyngioma } \\
(n=17)\end{array}$ & $\begin{array}{c}\text { Healthy } \\
\text { normal children } \\
(n=22)\end{array}$ \\
\hline Peak heart rate (beats $/ \mathrm{min}$ ) & $182 \pm 13$ & $188 \pm 12$ \\
\hline Basal diastolic BP (mmHg) & $70 \pm 11$ & $70 \pm 11$ \\
\hline Peak diastolic BP $(\mathrm{mmHg})$ & $70 \pm 11$ & $69 \pm 13$ \\
\hline Basal systolic BP (mmHg) & $112 \pm 15$ & $114 \pm 16$ \\
\hline Peak systolic BP $(\mathrm{mmHg})$ & $152 \pm 21^{\dagger}$ & $181 \pm 30$ \\
\hline Systolic BP increment $(\mathrm{mmHg})$ & $40 \pm 17^{\dagger}$ & $67 \pm 23$ \\
\hline $\mathrm{FVC}(\mathrm{ml})$ & $3049 \pm 819$ & $3391 \pm 759$ \\
\hline Percent of predicted FVC & $80 \pm 19$ & $91 \pm 23$ \\
\hline $\mathrm{FEV}_{1}(\mathrm{ml})$ & $2691 \pm 740$ & $2986 \pm 690$ \\
\hline Percent of predicted $\mathrm{FEV}_{1}$ & $81 \pm 14$ & $93 \pm 25$ \\
\hline $\mathrm{FEV}_{1} / \mathrm{FVC}$ ratio & $0.87 \pm 0.11$ & $0.88 \pm 0.07$ \\
\hline Total ventilation (1/min) & $72 \pm 19$ & $78 \pm 20$ \\
\hline $\mathrm{VO}_{2 \max }(\mathrm{ml} / \mathrm{min})$ & $1787 \pm 691^{*}$ & $2275 \pm 576$ \\
\hline Maximal power output (W) & $138 \pm 60^{*}$ & $180 \pm 50$ \\
\hline $\mathrm{VCO}_{2 \max }(\mathrm{ml} / \mathrm{min})$ & $1992 \pm 650^{*}$ & $2577 \pm 639$ \\
\hline $\mathrm{VCO}_{2} / \mathrm{VO}_{2}$ at peak exercise & $1.14 \pm 0.12$ & $1.14 \pm 0.09$ \\
\hline $\mathrm{VO}_{2 \max } /$ body weight (ml/kg per min) & $29.0 \pm 9.8^{\dagger}$ & $37.8 \pm 10.9$ \\
\hline $\mathrm{VO}_{2 \max } /$ fat-free mass (ml/kg per min) & $39.4 \pm 9.8^{\dagger}$ & $49.5 \pm 10.8$ \\
\hline Ventilatory threshold ( $\%$ of $\left.\mathrm{VO}_{2 \max }\right)$ & $66 \pm 18 \%$ & $67 \pm 6.0$ \\
\hline
\end{tabular}

$\mathrm{BP}$, blood pressure; FVC, forced vital capacity; $\mathrm{FEV}_{1}$, forced expiratory volume in $1 \mathrm{~s} ; \mathrm{VCO}_{2} / \mathrm{VO}_{2}$, peak respiratory exchange rate. ${ }^{\star} P<0.05 ;{ }^{\dagger} P<0.01$. 


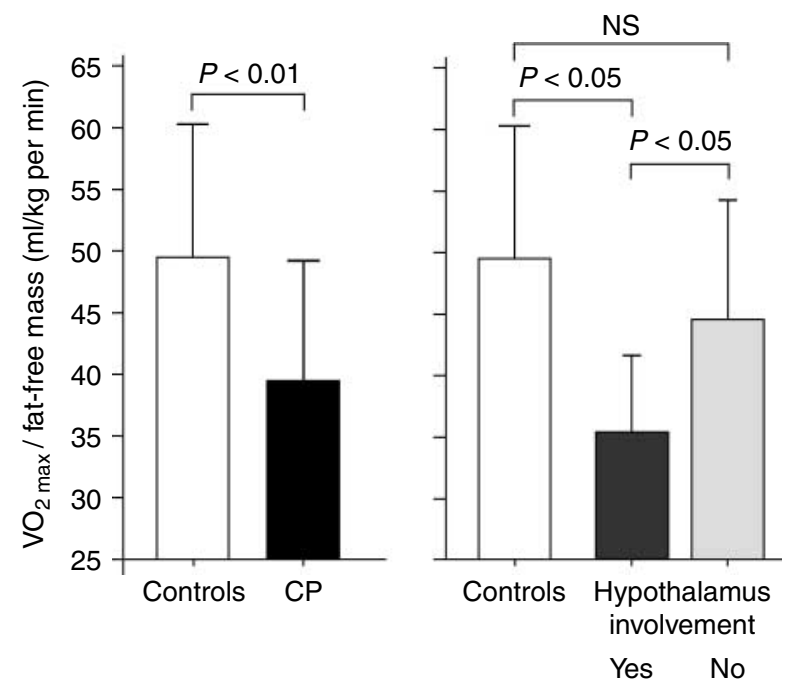

Figure $1 \mathrm{VO}_{2 \max }$ to fat-free mass in children with craniopharyngioma (CP) compared with controls (left panel) and in children with CP with and without hypothalamic involvement compared with controls (right panel) (mean \pm s.D.). Comparisons were performed using Student's $t$-tests and ANOVA and Fisher's least significant difference post hoc tests.

norepinephrine, and urinary catecholamine values. No correlation was found between any hormone value and the exercise capacity parameters. Similarly, no correlation was found between exercise capacity parameters and hydrocortisone or rhGH substitution and doses.

\section{Discussion}

Children and adolescents with surgically treated $\mathrm{CP}$ and adequate hormone substitution showed 20-25\% lower aerobic capacity (expressed as $\mathrm{VO}_{2 \max }$ to body weight as well as $\mathrm{VO}_{2 \max }$ to FFM) and $15-20 \%$ lower maximal systolic BP than healthy children with similar age, gender, pubertal stage, BMI, and weekly sports volume. This could contribute to the lack of resistance frequently expressed by these subjects. This difference was strongly related to hypothalamic involvement, whereas rhGH treatment was associated with a positive effect on aerobic capacity only in the absence of hypothalamic involvement. Daily epinephrine production and response to hypoglycemia were also decreased in these subjects. However, the degree of hormone deficiency was not related to the defect in aerobic capacity.

Maximal ability to utilize oxygen during exercise $\left(\mathrm{VO}_{2}\right.$ max $)$ depends on cardiac output, arterial oxygen content, and muscle oxygen extraction (31). In two recent studies, basal metabolic rate adjusted to total body weight was significantly lower in adult subjects with CP compared with controls (32), as well as in children with hypothalamic obesity (including CP) compared with simple obese controls (33). As basal metabolic rate is highly correlated with FFM and muscle mass, these findings could be in agreement with ours and suggest an alteration in muscle function, both at rest and during exercise. Differences in muscle fibers typology, glycogen and triglycerides content, enzymatic equipment (for glycolysis, tricarboxylic acid cycle, or $\beta$ oxidation), or mitochondrial density or activity could contribute to the differences between groups (34). Muscle biopsies would be needed to better understand this point better. In addition, factors unrelated to intrinsic properties of muscle fibers, such as neuromuscular activation, coordination, or ratio between reserves and use of energy, could also contribute to the differences between children with $\mathrm{CP}$ and normal controls and remain to be studied.

The difference in aerobic capacity between children with $\mathrm{CP}$ and controls was clearly related to hypothalamic involvement in this study. Since the hypothalamus is known to be involved in the control of energy homeostasis, including skeletal muscle energetic demand, through hormone production, as well as neural circuitries, undetermined factors linked to hypothalamic involvement may alter aerobic capacity (35). Alternatively, non-physiological pituitary hormone replacement (as the replacement of pituitary hormones hardly reproduces normal physiology) or hormone non-replacement (as for epinephrine) could possibly lead to altered aerobic capacity. Although

Table 3 Multiway ANOVA of $\mathrm{VO}_{2 \max }$ to fat-free mass (FFM). Parameter estimates were expressed as mean \pm s.D. $\mathrm{GH}$ replacement $(\mathrm{no}=0$, yes $=1)$ and hypothalamic involvement $(\mathrm{no}=0$, yes $=1)$ were explanatory variables and gender was a covariate.

\begin{tabular}{|c|c|c|c|c|c|}
\hline $\mathrm{VO}_{2 \max } / \mathrm{FFM}(\mathrm{ml} / \mathrm{kg}$ per $\min )\left(R^{2}=0.64\right)$ & df & $\begin{array}{l}\text { Parameter } \\
\text { estimates }\end{array}$ & $\begin{array}{c}\text { Mean } \\
\text { square }\end{array}$ & $\boldsymbol{F}$ & $\boldsymbol{P}$ \\
\hline Gender $(F=0 ; M=1)$ & 1 & $7.7 \pm 3.9$ & 185.0 & 3.99 & 0.07 \\
\hline Hypothalamic involvement ( $\mathrm{no}=0$; yes $=1$ ) & 1 & $-20.6 \pm 6.2$ & 382.7 & 8.25 & 0.01 \\
\hline rhGH treatment $($ no $=0$, yes $=1)$ & 1 & $-5.2 \pm 4.4$ & 61.2 & 1.32 & 0.27 \\
\hline Hypothalamic involvement $\times$ rhGH $R x$ & 1 & & 301.5 & 6.50 & 0.03 \\
\hline$(\mathrm{HT}=0 ;$ rhGH $\mathrm{Rx}=0)$ & & 0 & & & \\
\hline$(\mathrm{HT}=0 ;$ rhGH Rx $=1)$ & & $18.7 \pm 7.3$ & & & \\
\hline$(H T=1 ;$ rhGH $R x=0)$ & & 0 & & & \\
\hline$(H T=1 ; r h G H R x=1)$ & & 0 & & & \\
\hline Error & 12 & & 46.4 & & \\
\hline
\end{tabular}

rhGH Rx, rhGH treatment. 
Table 4 Catecholamine values in patients with craniopharyngioma and in healthy short controls. Urinary catecholamine excretion was expressed as amount per day per unit of body surface area. The results are given as mean \pm s.D. Normative data were obtained from a group of 17 short children comparable for age, gender, and pubertal stage (see Materials and methods section). Comparisons between groups were performed using Student's $t$-tests.

\begin{tabular}{|c|c|c|}
\hline & $\begin{array}{l}\text { Craniopharyngioma } \\
\qquad(n=17)\end{array}$ & $\begin{array}{l}\text { Normative data in } 17 \text { healthy } \\
\text { short children mean } \\
\text { (5th-95th percentiles) }\end{array}$ \\
\hline \multicolumn{3}{|l|}{ Insulin-induced hypoglycemia } \\
\hline Peak plasma epinephrine (ng/l) & $553 \pm 348^{*}$ & $914(330-1390)$ \\
\hline Peak plasma norepinephrine (ng/l) & $508 \pm 249^{*}$ & $308(180-590)$ \\
\hline \multicolumn{3}{|l|}{ Orthostatic test } \\
\hline Fold increase in plasma epinephrine & $1.1 \pm 0.2$ & $1.1(0.6-1.5)$ \\
\hline Fold increase in plasma norepinephrine & $2.1 \pm 0.8$ & $2.1(1.3-2.9)$ \\
\hline \multicolumn{3}{|l|}{ Urinary catecholamines } \\
\hline Epinephrine $\left(\mu \mathrm{g} / \mathrm{dm}^{2}\right)$ & $4.1 \pm 3.5^{\star}$ & $9.2(2.4-15.3)$ \\
\hline Norepinephrine $\left(\mu \mathrm{g} / \mathrm{dm}^{2}\right)$ & $18.8 \pm 9.1$ & $14.9(11.9-20.1)$ \\
\hline
\end{tabular}

${ }^{\star} P<0.05$ craniopharyngioma vs controls.

we did not find any statistical relationship between catecholamine measurements and parameters of aerobic performance, this did not mean the absence of involvement of catecholamines. Notably, plasma epinephrine and norepinephrine measurements in response to ITT or urinary catecholamine measurements gave no precise indication on local in/out flow, or number or sensitivity of receptors to the hormones. Further studies, including at least sequential plasma catecholamine measurements during exercise, would be required.

Shifts in energy substrate mobilization and utilization are known to occur as exercise intensity increases: there is a progressive increase in the relative contribution of carbohydrate oxidation and a corresponding decrease in the relative contribution of fat oxidation to energy expenditure (36). On the other hand, fat utilization during exercise has been shown to be higher in children compared with older subjects (34). Many steps in substrate mobilization and utilization are under hormonal control, including not only catecholamines but also GH and insulin (34); for instance, catecholamines were shown to increase muscle glycogenolysis and glycolysis (37). The difference in catecholamine production between the children with $\mathrm{CP}$ and the controls could therefore contribute to differences in exercise tolerance during the cycle ergometer test (34).

Cardiac function could also be altered in children with CP. In studies on adults with combined pituitary hormone deficiency with and without GH replacement, cardiac output investigated at rest was not different from that of controls $(38,39)$. In another study on 18 GHD adults with no rhGH treatment and appropriate replacement for other pituitary hormone deficiencies, cardiac output and peripheral vascular resistance at rest and during exercise were comparable to those of controls $(40,41)$, whereas maximal systolic BP was lower, as in our study: the authors suggested that this was due to a lower pressure-generating capacity of the heart. We did not perform systematic cardiac and vascular evaluation in our study and we are not aware of such evaluation in previous studies on subjects with CP.

In several studies, subjects with $\mathrm{CP}$ were less active than healthy subjects and were also more obese $(8,32)$, both factors possibly contributing to the differences in $\mathrm{VO}_{2 \max }$. In this study, the children with $\mathrm{CP}$ were comparable to the controls for BMI SDS, percent fat mass, FFM, and weekly strenuous sports volume. In addition, the differences in $\mathrm{VO}_{2 \max }$ persisted when adjusted to body weight as well as FFM, thus indicating that it was independent of body composition. We did not measure light physical activities, such as the number of daily steps using a pedometer. However, our children went to school as did the age-matched children, and they had comparable habits regarding extracurricular activities. We therefore believe that the difference in $\mathrm{VO}_{2 \max }$ could not have been due to unmeasured differences in light physical activities. Theoretically, an alteration in ventilatory function and a defect in oxygen transport by hemoglobin would also influence $\mathrm{VO}_{2 \max }$ (31). As all measured respiratory parameters (forced vital capacity, total ventilation, forced expiratory volume in $1 \mathrm{~s}$ ), hemoglobin concentration, and capillary oxygen content were normal in our subjects with $\mathrm{CP}$, the implication of such factors in the lower aerobic capacity was unlikely.

In two recent meta-analyses including a few hundred adult GH-treated patients compared with untreated subjects, $\mathrm{VO}_{2 \max }$ increased by about $9 \%$ with rhGH treatment $(11,42)$. However, this was observed in adults with AO GHD, and not in those with CO GHD. Here, we found that the positive effect of rhGH treatment on $\mathrm{VO}_{2 \max }$ in children with $\mathrm{CP}$ was only observed when there was no hypothalamic involvement, whereas it was not apparent when considering only rhGH treatment independently of hypothalamic involvement. This might explain the apparent 
discrepancies between studies on adults and suggested that the cause of the GHD should be taken into account in the analyses of rhGH replacement effect. However, the number of subjects in this study was small and our findings need to be confirmed in larger studies.

In conclusion, we found that children and adolescents with surgically treated CP showed decreases in maximal systolic BP and aerobic capacity during an exercise test, despite adequate hormone substitution. This difference with controls was strongly related to hypothalamic involvement, whereas aerobic capacity was improved by rhGH treatment only in subjects without hypothalamic involvement. Whether these declines would be improved by specific treatment remains to be determined.

\section{Declaration of interest}

The authors declare that there is no conflict of interest that could be perceived as prejudicing the impartiality of the research reported.

\section{Funding}

This research did not receive any specific grant from any funding agency in the public, commercial or not-for-profit sector.

\section{Acknowledgements}

We are thankful to Dr A Le Bouil (Angers University Hospital, France) for the catecholamine measurements and to Pr P Mercier (Angers University Hospital, France), neurosurgeon, who took care of the patients.

\section{References}

1 Dekkers OM, Biermasz NR, Smit JW, Groot LE, Roelfsema F, Romijn JA \& Pereira AM. Quality of life in treated adult craniopharyngioma patients. European Journal of Endocrinology 2006154 483-489. (doi:10.1530/eje.1.02114)

2 Pedreira CC, Stargatt R, Maroulis H, Rosenfeld J, Maixner W, Warne GL \& Zacharin MR. Health related quality of life and psychological outcome in patients treated for craniopharyngioma in childhood. Journal of Pediatric Endocrinology and Metabolism 200619 15-24. (doi:10.1515/JPEM.2006.19.1.15)

3 Sands SA, Milner JS, Goldberg J, Mukhi V, Moliterno JA, Maxfield C \& Wisoff JH. Quality of life and behavioral follow-up study of pediatric survivors of craniopharyngioma. Journal of Neurosurgery 2005103 302-311. (doi:10.3171/ped.2005.103.4.0302)

4 Kendall-Taylor P, Jonsson PJ, Abs R, Erfurth EM, KoltowskaHaggstrom M, Price DA \& Verhelst J. The clinical, metabolic and endocrine features and the quality of life in adults with childhood-onset craniopharyngioma compared with adult-onset craniopharyngioma. European Journal of Endocrinology 2005152 557-567. (doi:10.1530/eje.1.01877)

5 Poretti A, Grotzer MA, Ribi K, Schonle E \& Boltshauser E. Outcome of craniopharyngioma in children: long-term complications and quality of life. Developmental Medicine and Child Neurology 200446 220-229. (doi:10.1111/j.1469-8749.2004.tb00476.x)

6 Harz KJ, Muller HL, Waldeck E, Pudel V \& Roth C. Obesity in patients with craniopharyngioma: assessment of food intake and movement counts indicating physical activity. Journal of Clinical Endocrinology and Metabolism 200388 5227-5231. (doi:10. 1210/jc.2002-021797)
7 Waber DP, Pomeroy SL, Chiverton AM, Kieran MW, Scott RM, Goumnerova LC \& Rivkin MJ. Everyday cognitive function after craniopharyngioma in childhood. Pediatric Neurology $20063 \mathbf{4}$ 13-19. (doi:10.1016/j.pediatrneurol.2005.06.002)

8 Karavitaki N, Cudlip S, Adams CB \& Wass JA. Craniopharyngiomas. Endocrine Reviews 200627 371-397. (doi:10.1210/er. 2006-0002)

9 Gibney J, Healy ML \& Sonksen PH. The growth hormone/insulinlike growth factor-I axis in exercise and sport. Endocrine Reviews 200728 603-624. (doi:10.1210/er.2006-0052)

10 Woodhouse LJ, Mukherjee A, Shalet SM \& Ezzat S. The influence of growth hormone status on physical impairments, functional limitations, and health-related quality of life in adults. Endocrine Reviews 200627 287-317. (doi:10.1210/er.2004-0022)

11 Widdowson WM \& Gibney J. The effect of growth hormone replacement on exercise capacity in patients with GH deficiency: a metaanalysis. Journal of Clinical Endocrinology and Metabolism 200893 4413-4417. (doi:10.1210/jc.2008-1239)

12 Bengtsson BA, Abs R, Bennmarker H, Monson JP, FeldtRasmussen U, Hernberg-Stahl E, Westberg B, Wilton P \& Wuster $C$. The effects of treatment and the individual responsiveness to growth hormone $(\mathrm{GH})$ replacement therapy in 665 GH-deficient adults. KIMS Study Group and the KIMS International Board. Journal of Clinical Endocrinology and Metabolism 199984 3929-3935. (doi:10.1210/jc.84.11.3929)

13 Goran M, Fields DA, Hunter GR, Herd SL \& Weinsier RL. Total body fat does not influence maximal aerobic capacity. International Journal of Obesity and Related Metabolic Disorders $20002 \mathbf{2 4}$ 841-848. (doi:10.1038/sj.ijo.0801241)

14 Sunnegardh J \& Bratteby LE. Maximal oxygen uptake, anthropometry and physical activity in a randomly selected sample of 8 and 13 year old children in Sweden. European Journal of Applied Physiology and Occupational Physiology 198756 266-272. (doi:10.1007/BF00690891)

15 Prioux J, Ramonatxo M, Mercier J, Granier P, Mercier B \& Prefaut C. Changes in maximal exercise ventilation and breathing pattern in boys during growth: a mixed cross-sectional longitudinal study. Acta Physiologica Scandinavica $1997161447-458$. (doi:10.1046/j.1365-201X.1997.00245.x)

16 Coutant R, Maurey H, Rouleau S, Mathieu E, Mercier P, Limal JM \& Le Bouil A. Defect in epinephrine production in children with craniopharyngioma: functional or organic origin? Journal of Clinical Endocrinology and Metabolism $2003 \mathbf{8 8} 5969-5975$. (doi:10.1210/jc.2003-030552)

17 Roth CL, Hunneman DH, Gebhardt U, Stoffel-Wagner B, Reinehr T \& Muller HL. Reduced sympathetic metabolites in urine of obese patients with craniopharyngioma. Pediatric Research 2007 61 496-501. (doi:10.1203/pdr.0b013e3180332cd6)

18 Schofl C, Schleth A, Berger D, Terkamp C, von zur Muhlen A \& Brabant G. Sympathoadrenal counterregulation in patients with hypothalamic craniopharyngioma. Journal of Clinical Endocrinology and Metabolism 200287 624-629. (doi:10.1210/ jc.87.2.624)

19 Puget S, Garnett M, Wray A, Grill J, Habrand JL, Bodaert N, Zerah M, Bezerra M, Renier D, Pierre-Kahn A \& Sainte-Rose C. Pediatric craniopharyngiomas: classification and treatment according to the degree of hypothalamic involvement. Journal of Neurosurgery 2007106 3-12. (doi:10.3171/ped.2007.106.1.3)

20 Sempe M, Pedron G \& Roy-Pernot MP. Auxologie, Methodes et Sequences Paris: Theraplix Public, 1979.

21 Rolland-Cachera MF, Cole TJ, Sempe M, Tichet J, Rossignol C \& Charraud A. Body mass index variations: centiles from birth to 87 years. European Journal of Clinical Nutrition 1991 45 13-21.

22 Horlick M, Arpadi SM, Bethel J, Wang J, Moye J Jr, Cuff P, Pierson RN Jr \& Kotler D. Bioelectrical impedance analysis models for prediction of total body water and fat-free mass in healthy and HIV-infected children and adolescents. American Journal of Clinical Nutrition $200276991-999$.

23 Wabitsch M, Braun U, Heinze E, Muche R, Mayer H, Teller W \& Fusch C. Body composition in 5-18-y-old obese children and 
adolescents before and after weight reduction as assessed by deuterium dilution and bioelectrical impedance analysis. American Journal of Clinical Nutrition 199664 1-6.

24 Marshall WA \& Tanner JM. Variations in pattern of pubertal changes in girls. Archives of Disease in Childhood 196944 291-303. (doi:10.1136/adc.44.235.291)

25 Marshall WA \& Tanner JM. Variations in the pattern of pubertal changes in boys. Archives of Disease in Childhood 197045 13-24. (doi:10.1136/adc.45.239.13)

26 Washington RL, Bricker JT, Alpert BS, Daniels SR, Deckelbaum RJ, Fisher EA, Gidding SS, Isabel-Jones J, Kavey RE \& Marx GR. Guidelines for exercise testing in the pediatric age group. From the Committee on Atherosclerosis and Hypertension in Children, Council on Cardiovascular Disease in the Young, American Heart Association. Circulation 199490 2166-2179.

27 Quanjer PH, Borsboom GJ, Brunekreef B, Zach M, Forche G, Cotes JE, Sanchis J \& Paoletti P. Spirometric reference values for white European children and adolescents: Polgar revisited. Pediatric Pulmonology 199519 135-142. (doi:10.1002/ppul.1950190209)

28 Borg GA. Psychophysical bases of perceived exertion. Medicine and Science in Sports and Exercise 198214 377-381.

29 Premel-Cabic A, Turcant A, Cailleux A \& Allain P. Determination de la noradrenaline plasmatique par chromatographie liquide haute pression en mode automatique avec detection electrochimique. Pathologie Biologie 198332 739-742.

30 Premel-Cabic A, Turcant A \& Allain P. Normal reference intervals for free catecholamines and their acid metabolites in 24-h urine from children, as determined by liquid chromatography with amperometric detection. Clinical Chemistry 198632 1585-1587.

31 Betik AC \& Hepple RT. Determinants of $\mathrm{VO}_{2 \max }$ decline with aging: an integrated perspective. Applied Physiology, Nutrition, and Metabolism 200833 130-140. (doi:10.1139/H07-174)

32 Holmer H, Pozarek G, Wirfalt E, Popovic V, Ekman B, Bjork J \& Erfurth EM. Reduced energy expenditure and impaired feeding-related signals but not high energy intake reinforces hypothalamic obesity in adults with childhood onset craniopharyngioma. Journal of Clinical Endocrinology and Metabolism 201095 5395-5402. (doi:10.1210/jc.2010-0993)

33 Shaikh MG, Grundy RG \& Kirk JM. Reductions in basal metabolic rate and physical activity contribute to hypothalamic obesity. Journal of Clinical Endocrinology and Metabolism 200893 2588-2593. (doi:10.1210/jc.2007-2672)
34 Riddell MC. The endocrine response and substrate utilization during exercise in children and adolescents. Journal of Applied Physiology 2008105 725-733. (doi:10.1152/japplphysiol.00031.2008)

35 Vianna CR \& Coppari R. A treasure trove of hypothalamic neurocircuitries governing body weight homeostasis. Endocrinology 2011152 11-18. (doi:10.1210/en.2010-0778)

36 Martin WH III \& Klein S. Use of endogenous carbohydrate and fat as fuels during exercise. Proceedings of the Nutrition Society 1998 57 49-54. (doi:10.1079/PNS19980008)

37 Febbraio MA, Lambert DL, Starkie RL, Proietto J \& Hargreaves M. Effect of epinephrine on muscle glycogenolysis during exercise in trained men. Journal of Applied Physiology 199884 465-470.

38 Irving RJ, Carson MN, Webb DJ \& Walker BR. Peripheral vascular structure and function in men with contrasting $\mathrm{GH}$ levels. Journal of Clinical Endocrinology and Metabolism 200287 3309-3314. (doi:10.1210/jc.87.7.3309)

39 Andreassen M, Faber J, Kjaer A, Petersen CL \& Kristensen LO. Cardiac effects of 3 months treatment of acromegaly evaluated by magnetic resonance imaging and B-type natriuretic peptides. Pituitary 201013 329-336. (doi:10.1007/s11102010-0240-9)

40 Moisey R, Barker D, Lewis N, Sharp L, Clements RE, Goldspink DF, Tan LB \& Orme S. Reduced cardiac functional reserve and quality of life in adults with GH deficiency. Clinical Endocrinology 200971 543-548. (doi:10.1111/j.1365-2265.2009.03560.x)

41 Moisey R, Orme S, Barker D, Lewis N, Sharp L, Clements RE, Goldspink DF \& Tan LB. Cardiac functional reserve is diminished in growth hormone-deficient adults. Cardiovascular Therapeutics 200927 34-41. (doi:10.1111/j.1755-5922.2009.00073.x)

42 Rubeck KZ, Bertelsen S, Vestergaard P \& Jorgensen JO. Impact of growth hormone $(\mathrm{GH})$ substitution on exercise capacity and muscle strength in GH-deficient adults: a meta-analysis of blinded, placebo-controlled trials. Clinical Endocrinology 200971 860-866. (doi:10.1111/j.1365-2265.2009.03592.x)

Received 23 August 2011

Revised version received 2 November 2011

Accepted 17 November 2011 